\title{
Interactive comment on "Tectono-thermal
} evolution of Oman's Mesozoic passive continental margin under the obducting Semail Ophiolite: a case study Jebel Akhdar, Oman" by Arne Grobe et al.

Arne Grobe et al.

arne.grobe@emr.rwth-aachen.de

Received and published: 1 October 2018

Dear Prof. Aldega, Thank you for your extensive and constructive feedback. We adapted the manuscript accordingly and all suggestions will be implemented in the resubmitted Manuscript. Especially, we extended on the meaning and importance of the study in the Introduction and revised and extended the data description. The discussion now also elaborates on the errors associated with the temperature predictions. You suggested to show "the thermal maturity curve fitting, the solid bitumen data as a function of depth". Such information has been published in a previous paper in our 
group and would be a repetition here, so we will just refer to the existing paper more clearly. Also we noted that the presented solid bitumen data do not cover a wide stratigraphic range; therefore, a depth plot is less meaningful than in other regional settings. We tried to extend the sampled intervals but were not successful to find additional solid bitumen (or even vitrinite) bearing strata within the carbonate platform. We agree that the transformation of solid bitumen reflectance to vitrinite reflectance has some pitfalls and should be avoided when possible. However, this is mainly true at low levels of maturation where uncertainties with respect to this transformation are much more important than at high levels of maturation. The optical properties of organic particles convert more and more at high levels of maturity. We think that the presented temperature estimates are helpful, but we agree that we should extend the discussion of associated uncertainties. We are looking forward to present a reorganized manuscript with updated figures and highlighted tracked changes together with a detailed revision of your comments soon.

Kind regards,

Arne Grobe \& Coauthors

Interactive comment on Solid Earth Discuss., https://doi.org/10.5194/se-2018-78, 2018. 